\title{
Design Case of the E-19 AEOLUS Supersonic Business Jet
}

\author{
Howard Smith, ${ }^{*}$ and Yicheng Sun ${ }^{\dagger}$ \\ Cranfield University, Bedfordshire, MK43 OAL, UK
}

\begin{abstract}
This paper introduces the E-19 AEOLUS supersonic business jet designed by the authors (conceptual design) and a team of Staff and a team of graduate students (preliminary and detail design) from the Aerospace Vehicle Design MSc. The design is presented at the $\mathbf{5 0}^{\text {th }}$ anniversary of the first flight of Concorde and with growing interest from many aircraft design companies. An attractive design would still need the usual attributes of safety, security, comfort, reliability, performance and operational flexibility. This paper presents a design that attempts to address these issues. The details of cabin, structures, landing gear, systems, powerplants, etc. are designed. Low-boom low-drag technologies are applied to the design. The synthetic vision display and double drooping nose are introduced to increase the pilot's field of view. The resulting concept is challenging but could result in an aircraft well suited to meet a new market opportunity.
\end{abstract}

\section{Introduction}

$\mathrm{T}$ HE Low-Boom Low-Drag Supersonic Business Jet E-19 Aeolus project is born of the recent growing interest in recovering the field of civil supersonic aviation. This interest is influenced by the actual globalisation of the market, where time-saving is a concern of significant importance. A supersonic aircraft would allow a reduction in the flight time of conventional subsonic aircraft by as much as $50 \%$.

The E-19 Aeolus is a challenging project targeted at the 2025-2035 time frame well-suited to the most recent market forecast studies, which highlight the trend for future supersonic aviation (more specifically supersonic business jets). The design specifications are driven by these market trend studies, considering not just the performance, safety, reliability, comfort and operational capabilities to achieve success in the market but also, the requirements relating to emissions and sonic boom mitigation [1,2].

Exotic technologies were considered in the design to overcome configurational challenges. The use of a Synthetic Vision system, in the baseline design, was implemented to improve the pilot's view given the obstruction by the aircraft nose, due to its slenderness. A Hybrid Laminar Flow Control (HLFC) system was integrated into the airframe, increasing the aerodynamic efficiency of the aircraft and improving its performance.

Low-boom and low-drag are the main features of the E-19 Aeolus conceptual design. The low-drag characteristic allows achieving high aerodynamic efficiency in both subsonic and supersonic conditions, highlighted in several market studies as a constraint for success on the market. This aerodynamic efficiency would allow the reduction of the direct operating costs and would help to achieve the target range. The low-boom design is achieved constraining the maximum take-off mass and both wing and fuselage geometry. Low-boom features are also related to the slender characteristics of the aircraft.

\section{A Brief Review of the Group Design Project}

The idea of an aircraft Group Design Project (GDP) has evolved into a postgraduate master's programme in aerospace vehicle design. The aim of the project is to provide students with a virtual industrial environment where they follow industry standard procedures. It is a good example of problem based learning at postgraduate level. Students are prepared for roles as professional aerospace design engineers and experience design reviews. The overview of the E-19 GDP is shown in Fig. 1. The conceptual design has been generated in a multidisciplinary design analysis optimization environment called GENUS [3]. GENUS was developed by the Cranfield Aircraft Design Group. The environment is able to synthesize and analyze most aerospace vehicle concepts. GENUS has proven its capability in aircraft conceptual designs through a series novel aircraft studies [4-8]. The E-19 AEOLUS design is based on the low-boom low-drag supersonic business jet design research within the aircraft design group [9-12].

\footnotetext{
* Professor, School of Aerospace Transport and Manufacturing, AIAA Senior Member.

${ }^{\dagger}$ Research Fellow, School of Aerospace Transport and Manufacturing, AIAA Member.
} 


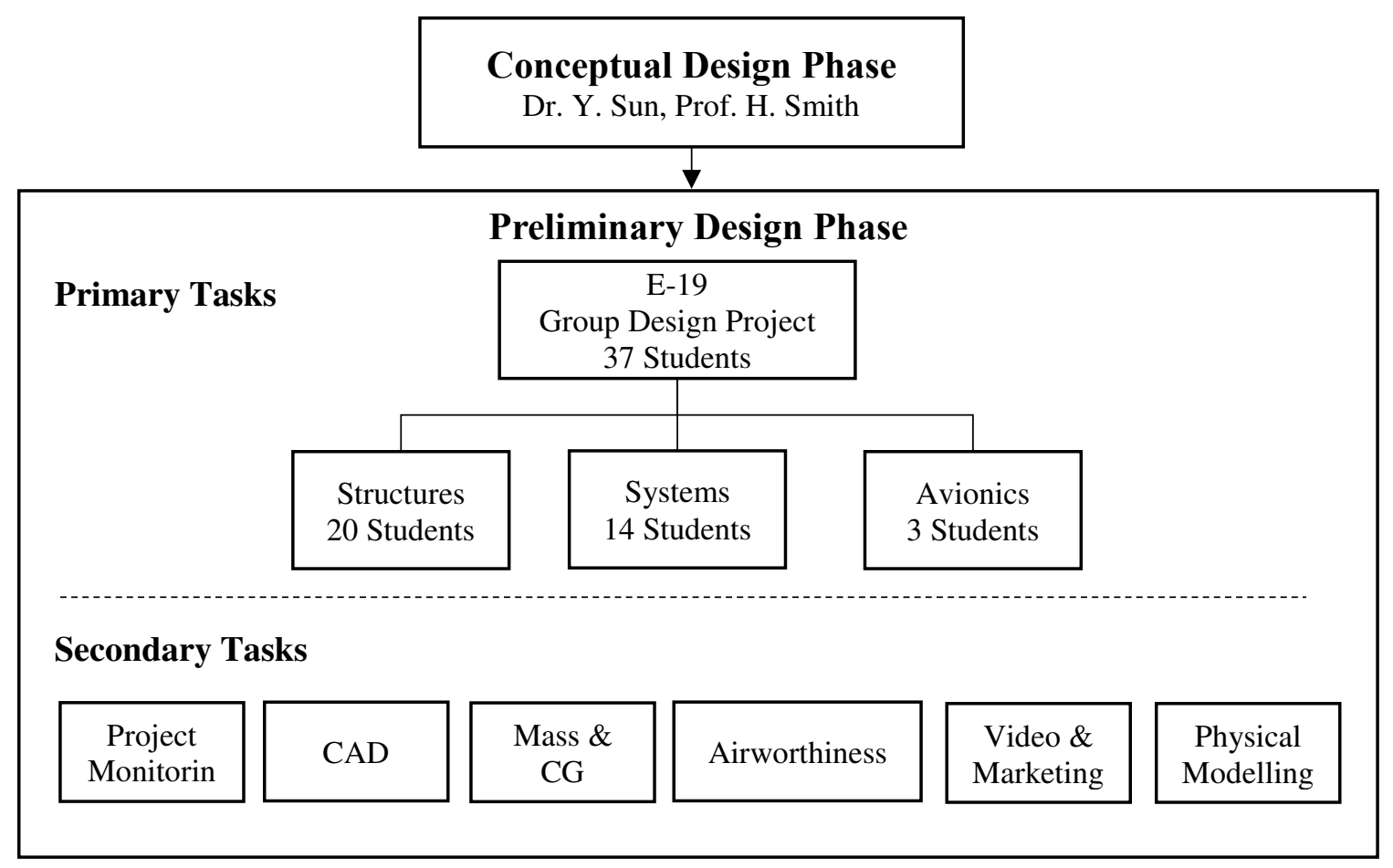

Fig. 1 Overview of the E-19 GDP organization

\section{E-19 AEOLUS Conceptual Design}

In the conceptual design phase, inter-disciplinary design is the main activity by simultaneously considering many tightly-coupled systems. Low- to medium-fidelity methods are applied to the design and analysis of the concept. The optimizers are essential for exploring a feasible solution and meeting certain design criteria (e.g. sonic boom intensity).

\section{A. Design Specifications}

The top-level requirements of a design are derived from the market or customer specifications. The mission requirements for the E-19 AEOLUS, shown in Table 1, have been analysed by the authors in a review paper [2], considering the environmental impacts, technological challenges, and market analysis. They are assumed to be the appropriate initial requirements for environmentally friendly and economically viable SSBJs.

Table 1 E-19 AEOLUS initial specification

\begin{tabular}{|c|c|}
\hline \multicolumn{2}{|c|}{ Certification Requirements } \\
\hline Specification Operational Specification \\
\hline Design Range & CS-25/ TSS \\
\hline Design Cruise Speed & $1.000 \mathrm{~nm}$ \\
\hline Maximum Cruise Altitude & $55,000 \mathrm{ft}$ \\
\hline Take-off Field Length & $1,315 \mathrm{~m}$ \\
\hline Landing Field Length & $1,022 \mathrm{~m}$ \\
\hline Maximum operating Mach Number & 1.95 \\
\hline Design Mach Number & 1.80 \\
\hline Cut-off Mach Number & 1.15 \\
\hline \multicolumn{2}{|c|}{ Environmental Specification } \\
\hline Community Noise & Stage 4 \\
\hline Sonic Boom intensity without engine & $0.91 \mathrm{psf}$ \\
\hline Sonic Boom intensity with engine & $1.09 \mathrm{psf}$ \\
\hline \multicolumn{2}{|c|}{ Structural Requirements } \\
\hline
\end{tabular}




\begin{tabular}{|c|c|}
\hline Airframe Life & 71,441 cycles \\
\hline Wing Span & $14.605 \mathrm{~m}$ \\
\hline Wing Gross Area & $154.384 \mathrm{~m}^{2}$ \\
\hline Leading-edge sweep (inboard) & $75.5^{\circ}$ \\
\hline Leading-edge sweep (outboard) & $70^{\circ}$ \\
\hline Fuselage Overall Length & $15.670 \mathrm{~m}$ \\
\hline Fuselage maximum Width & $1.980 \mathrm{~m}$ \\
\hline Track (outside width of outer wheels) & $4.749 \mathrm{~m}$ \\
\hline \multicolumn{2}{|c|}{ Capacities } \\
\hline Maximum Take-off Mass (MTOM) & $45,000 \mathrm{~kg}$ \\
\hline Maximum Landing Mass (MLM) & $36,000 \mathrm{~kg}$ \\
\hline Maximum Zero-Fuel Mass (ZFM) & $19,990 \mathrm{~kg}$ \\
\hline Operating Empty Mass (OEM) & $17,990 \mathrm{~kg}$ \\
\hline Design Payload ZFM & $1,250 \mathrm{~kg}$ \\
\hline Maximum Fuel Mass & $8,289 \mathrm{~kg}$ \\
\hline Passenger & 10 single class configuration \\
\hline \multicolumn{2}{|c|}{ Propulsion Plant } \\
\hline Engine length & 2 Mixed Flow Low-Bypass Turbofan \\
\hline Power at Seal Level & $3.116 \mathrm{~m}$ \\
\hline Sea Level Static T/O Thrust & $110.96 \mathrm{kN}$ \\
\hline
\end{tabular}

\section{B. General Layout}

The authors have analysed several different wing and fuselage combinations in a previous study [12] and found that a low-boom low-drag design should have uniform longitudinal volume and lift distributions. The fuselage is expected to be more slender and a highly-swept wing is expected to flatten the lift distribution. A horizontal tail is preferred rather than a canard as the horizontal tail can help to reduce the sonic boom signature in the aft region. The geometry layout of the SSBJ is presented in Fig. 2.

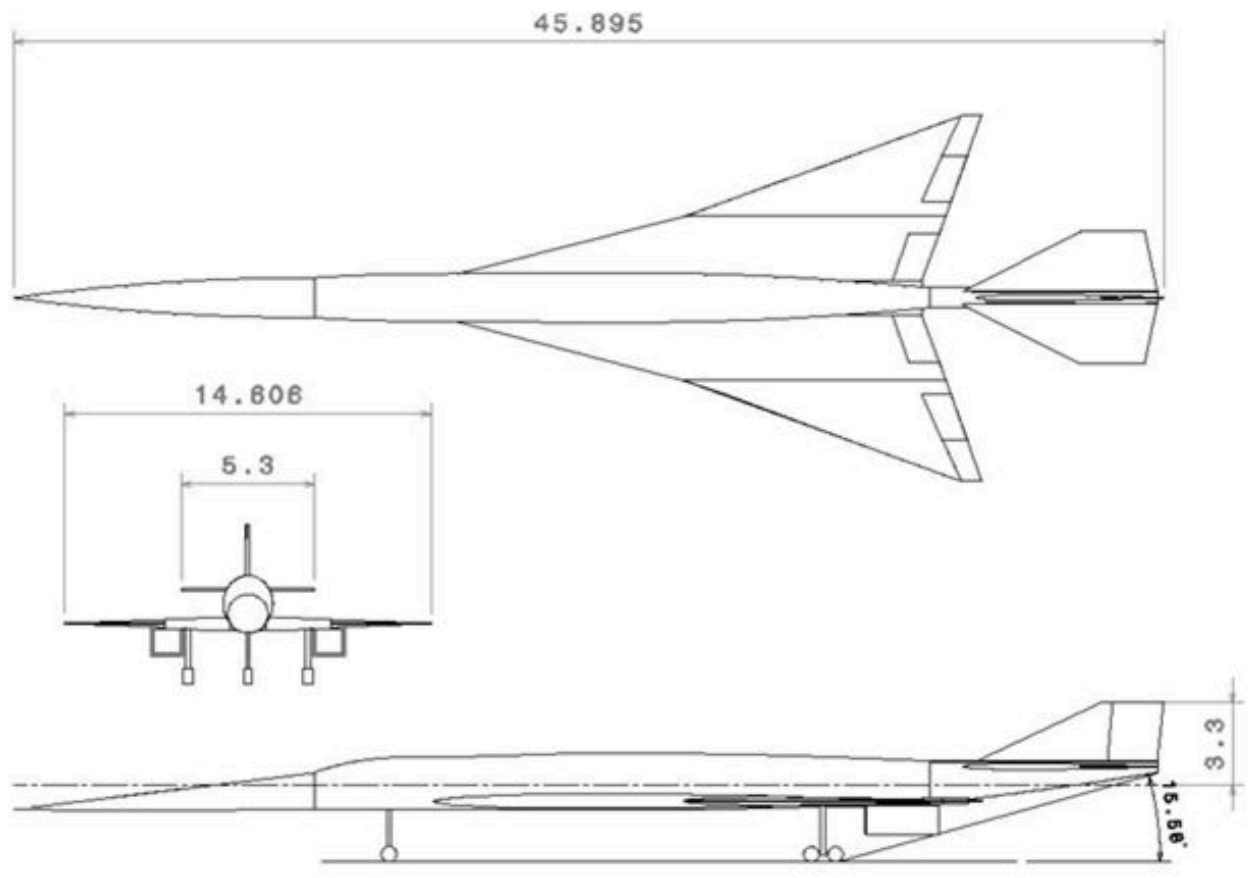

Fig. 2 General layout of the design 
A feature of the GENUS environment is the design and analysis of the packaging at the conceptual phase. The inner components are sized and positioned inside the outer mould line. The wing fuel tanks are designed to avoid interference with the main landing gear and control surfaces. The fuselage fuel tanks are introduced not only to accommodate the remainder of the mission fuel, but also to adjust the centre of gravity (CG) position to compensate for the aerodynamic centre changes with Mach number. The landing gear may ruin the layout [13], therefore, it is important to plan ahead at the conceptual phase. For the supersonic thin airfoil, checking the accommodation of the main landing gear is crucial. The final inside arrangement of the E-19 conceptual design can be found in Fig. 3.

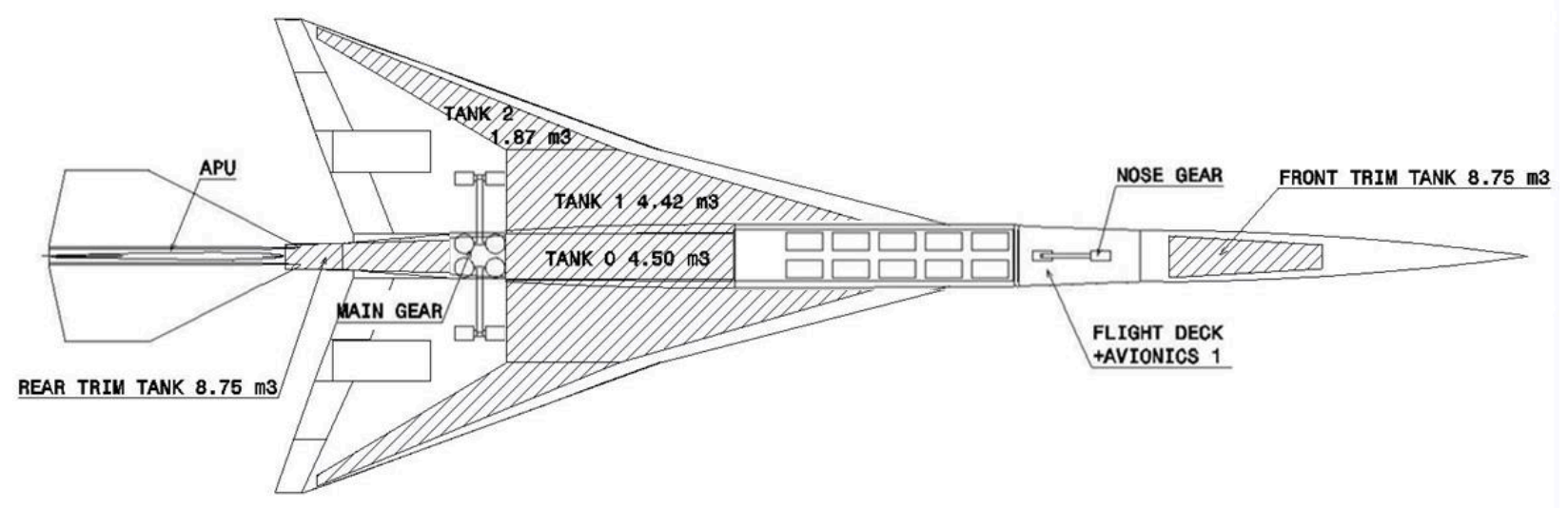

Fig. 3 Inside arrangement

\section{Aerodynamics}

The aerodynamic coefficients for the configuration were analysed mainly with PANAIR [14], with drag components corrected by the form factor method [15] and wave drag computing method [16]. The drag polar is plotted in Fig. 4.

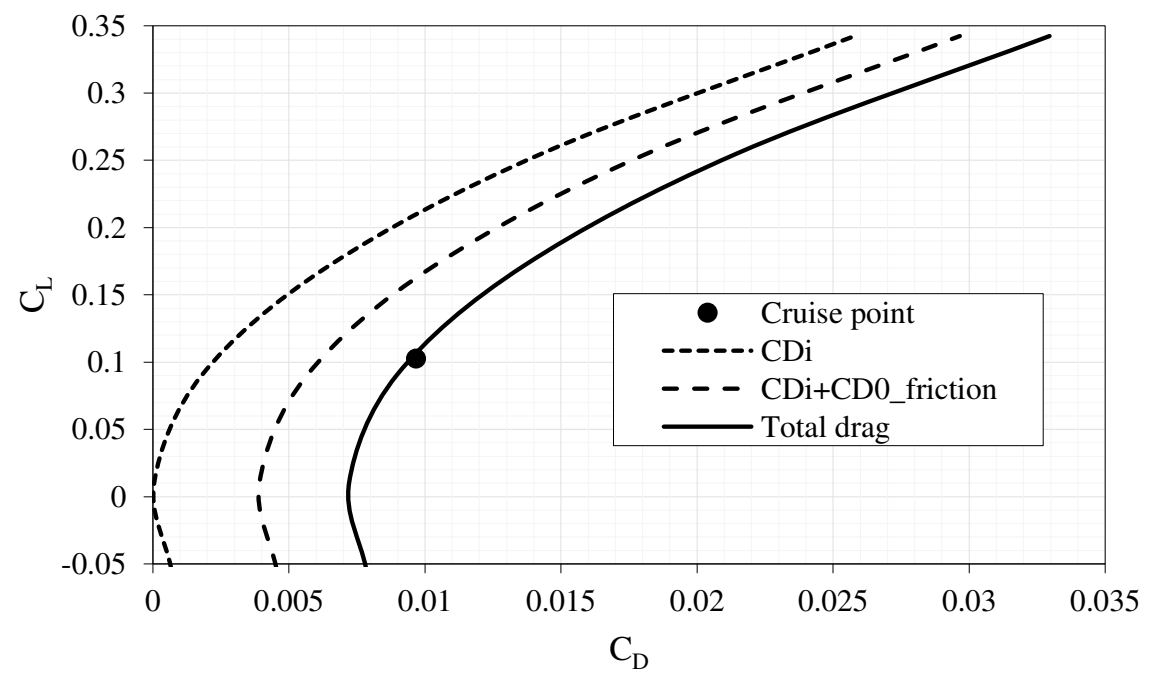

Fig. 4 Drag components and drag polar

The mission, outer surface and aerodynamics are frozen at the conceptual design stage. The preliminary design work of the GDP will focus on the structure design, systems integration and avionics system development. 


\section{E-19 AEOLUS Preliminary Design}

The preliminary design phase verifies the feasibility of the E-19 AEOLUS concept with an ever-increasing level of design and analysis detail.

\section{A. Cabin Layout}

The standard cabin layout has 10 seats, where each has an arm rest on one side which also contains a retractable table and control panel for entertainment. The cabin has a continuous ceiling light overhead and some reading lights above each seat. At the rear of the cabin, one galley is installed on the left side and one lavatory on the right side. The main design philosophy is to make the most use of the limited space, while providing a comfortable environment for passengers, as pictured in Fig. 5

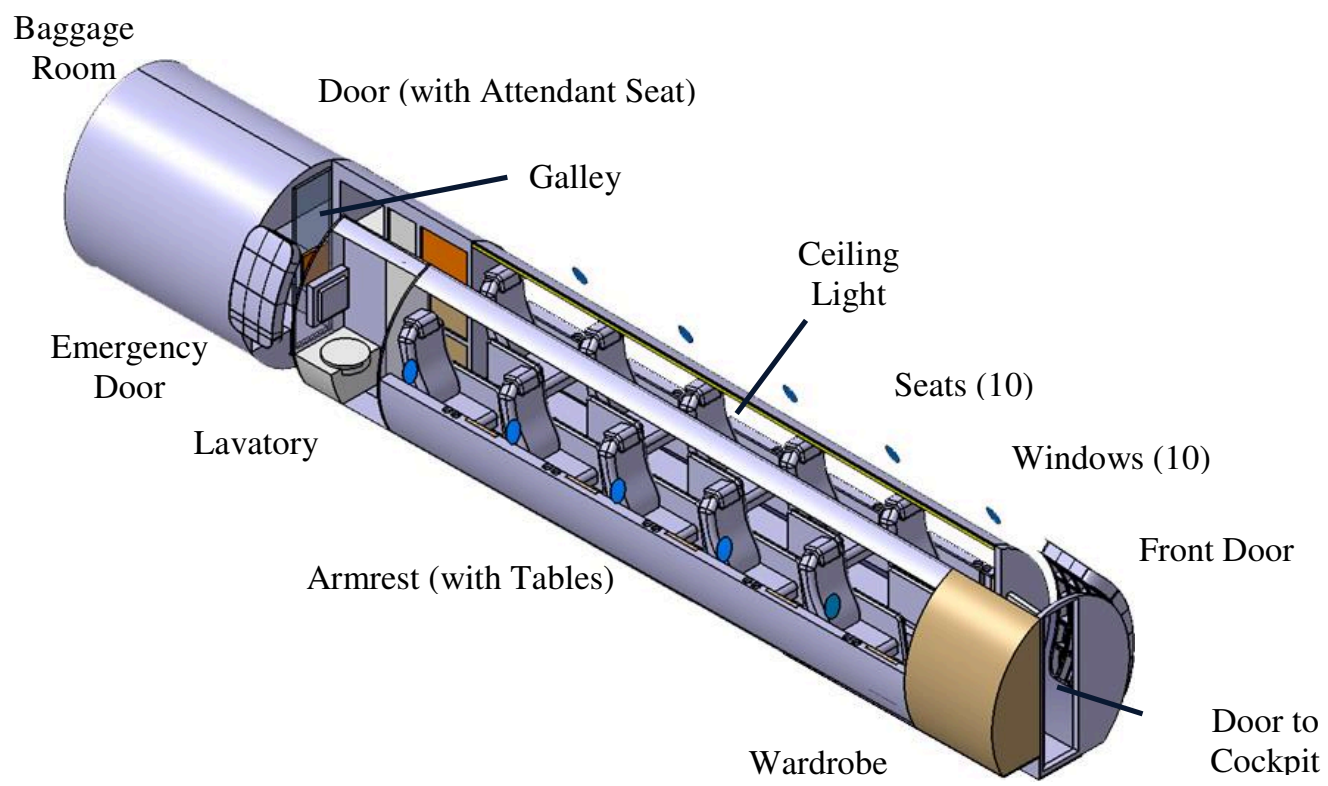

Fig. 5 Cabin layout

\section{B. Structure}

The main challenges for structural design include the thin wing aerofoil with its limited internal volume, engine installation, and material selection for high temperature and light weight. 


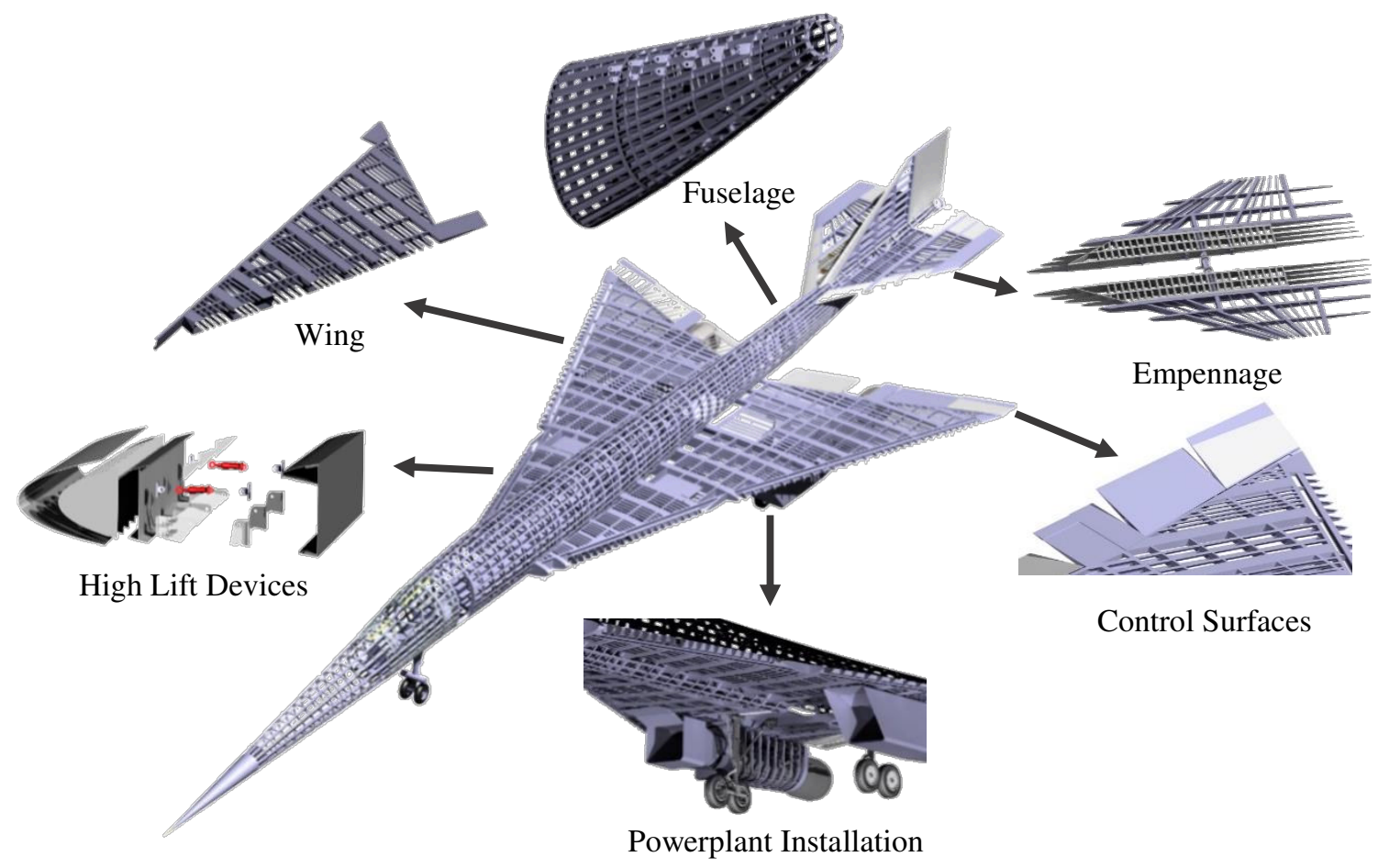

Fig. 6 Structural detail

The main design requirement for the wing is that it be able to stand a maximum service temperature of $95^{\circ} \mathrm{C}$. The material is full composite to achieve a light weight. Temperature resistance requirements have led to the wing structure being made of High Modulus carbon fibre except for the lower skin which has an intermediate modulus due to impact resistance requirements, as shown in Fig. 7.

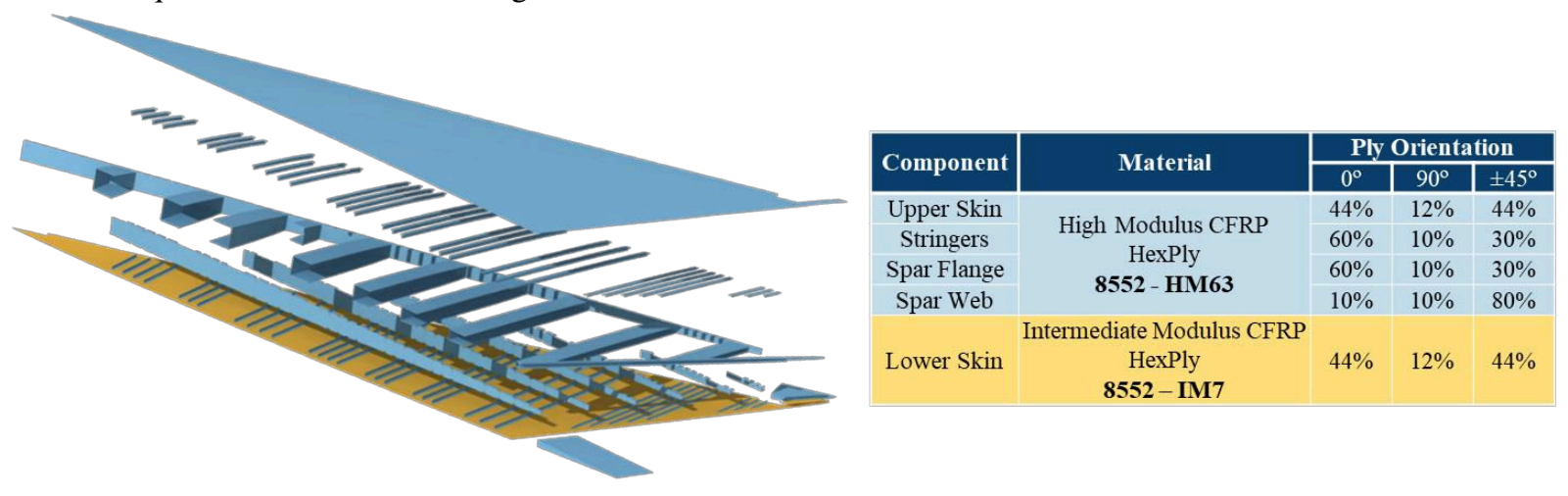

Fig. 7 Wing material selection and laminate layup

The engine is mounted via a bracket structure built around the main triangulated structure, designed in tension to optimise the use of composite materials, which picks up on the diametrically opposed trunnions located at the highpressure turbine casing. The critical loads acting on the structure result from the emergency landing cases and the excess torque due to an engine seizure in a time of 3 seconds. The beams contained within the triangulated structure consist of a hollow geometry to restrict such high torque loads caused by engine seizure. 


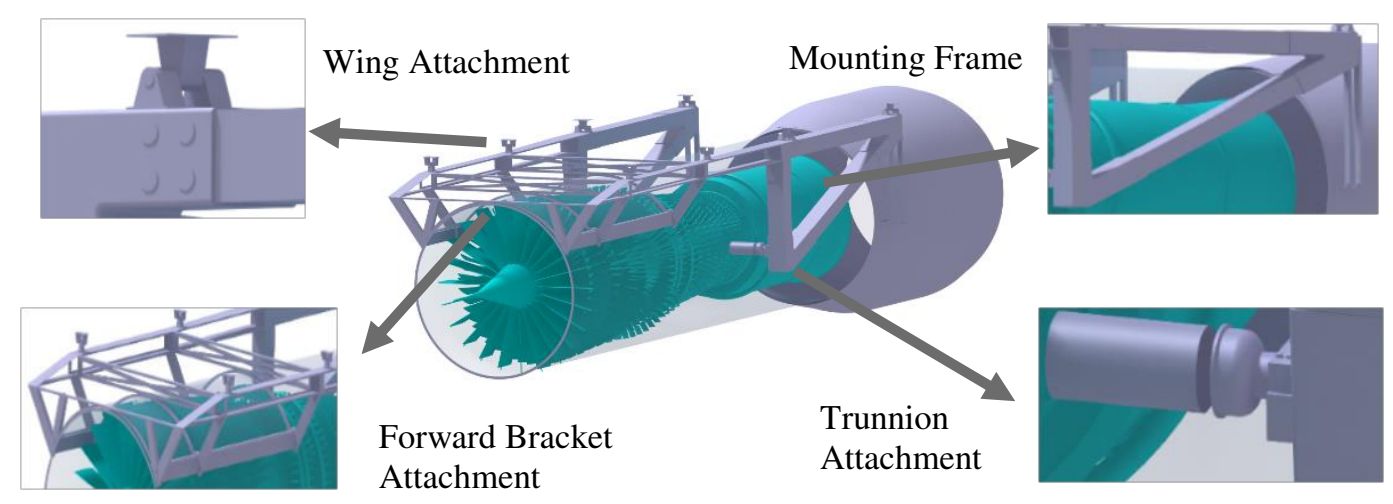

Fig. 8 Engine installation

The E-19 tailplane is not a conventional design, as the inboard part (inner tail) is fixed to the fuselage and the outboard part is all-moving, with a rotational capability from $-29^{\circ}$ to $+10^{\circ}$. The tailplane is designed using a multi-cell structure, having 5 spars and 3 ribs. The inboard rib is designed to carry the attachment with the inner tailplane. The structural components of the tailplane are manufactured from composite, HEXply IM7/8552 material. The reason behind the material selection is its ability to withstand high operating temperatures of up to $120^{\circ}$ as well as having a high strength to weight ratio. The lug attachments are made of titanium alloy Ti-6Al-4V, for coping with the strength density required as well as avoiding galvanic corrosion when used with the CFRP materials. The skin panels are stiffened with Zed-shaped stringers. The outer-tailplane is attached by lugs on the shaft located at $56 \%$ of the root chord from the horizontal tail apex.

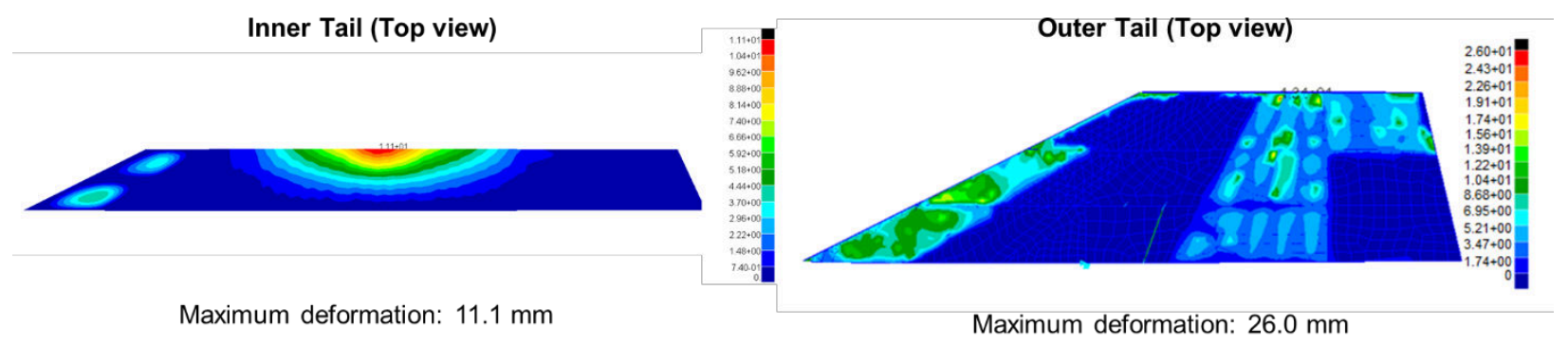

Fig. 9 FEM analysis for the horizontal tailplane

\section{Powerplant}

The engine has been modelled from the reference engine to a length of $3.116 \mathrm{~m}$ and $0.877 \mathrm{~m}$ diameter. The weight of the modelled engine is estimated to be $945.4 \mathrm{~kg}$ approximately. The engine has a bypass ratio of 0.36 . The modelled engine is a twin spool mixed flow augmented low bypass Turbofan engine. The engine has been integrated with the following sub-systems: Intake, Compressor (fan-face), Bypass splitter, 4LPC, 4HPC, Combustor, Mixer, 1HPT, 1LPT, Nozzle. The powerplant and relevant structures are shown in Fig. 10. 


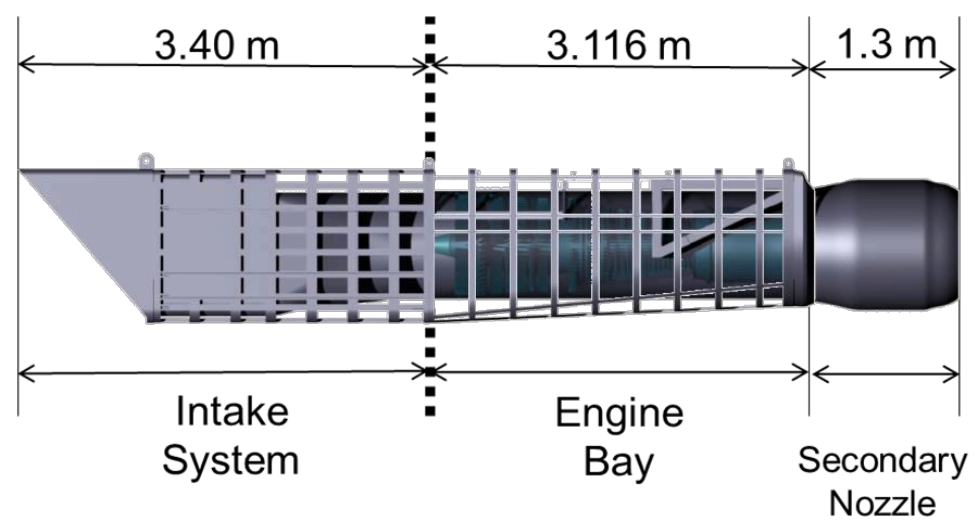

Fig. 10 Powerplant overall dimension

The E-19 has a variable geometry intake with three movable ramps, actuated by an electro mechanical actuation system. This design optimizes the shock system at the design conditions of the aircraft trough a variable geometry. The resulting nacelle length is estimated as $6.5 \mathrm{~m}$ with a subsonic diffuser of $2.6 \mathrm{~m}$. This diffuser houses the movable ramps, which are $0.6 \mathrm{~m}$ each.

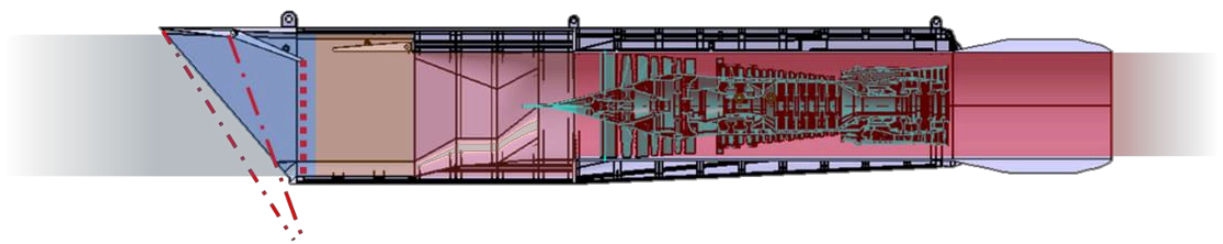

Fig. 11 Intake design

\section{Landing Gears}

The landing gear system is designed to be a more-electric system architecture, with a fly by wire system, which allows for improved redundancies and improved performance. The steering system is hydraulically actuated and mechanically controlled which allows the aircraft to have a turning radius of $20.1 \mathrm{~m}$ with a maximum steering angle of 60 degrees supporting a max torque of $45663 \mathrm{Nm}$.

The E-19 uses Electro Hydrostatic actuators (EHA) for the actuation of the landing gear with a retraction time of 7 seconds with a manual mechanically actuated gravity action failsafe for the extension of the nose landing gear. The system design utilizes maximum space horizontally to allow for proper integration within the aircraft fuselage.

The braking system uses EMA's electromechanical actuators and carbon brake packs with antiskid and autobrake functions. In order to mitigate the risk of a catastrophic incident, emergency actuators and control systems have been employed.

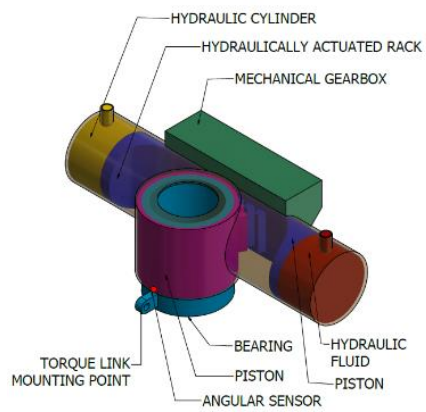

(a)

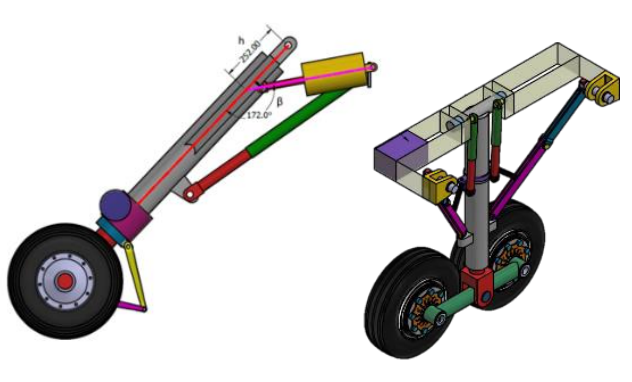

(b)

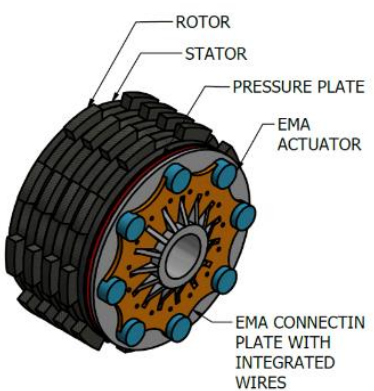

(c)

Fig. 12 (a) Steering System (b) Actuation System (c) Braking System 


\section{E. Systems}

The systems of E-19 include the fuel system, ice protection system, secondary power distribution system, environmental control system, and thermal management system, as pictured in Fig. 13.

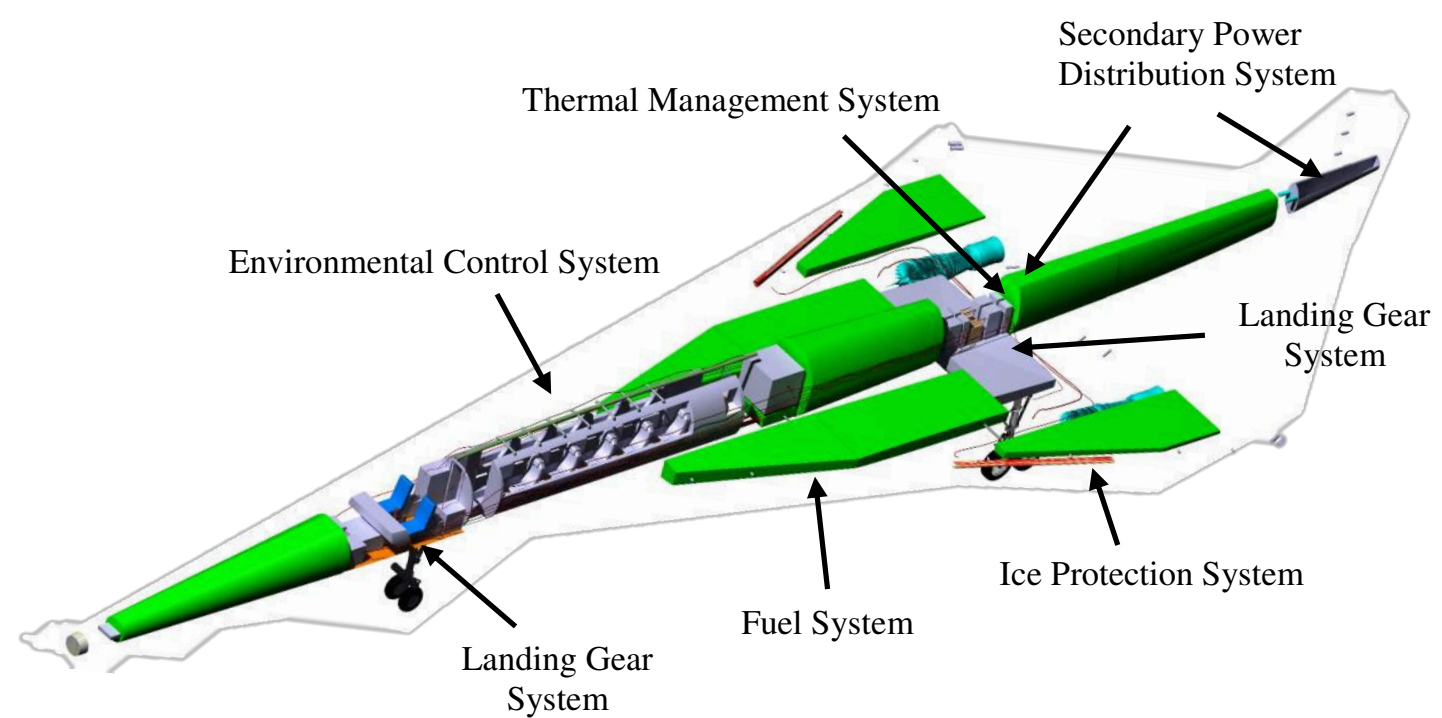

Fig. 13 Systems layout

The E-19 has 9 integral fuel tanks in the wings and fuselage, with a total volume capacity of $35.36 \mathrm{~m}^{3}$. The hybrid vent system is open during subsonic flight, but closed during high altitude cruise. A pressure of 2 psi is maintained with the help of pressure relief valves and the on-board inert gas generation system. The open vent system is sized for an emergency dive from 60,000ft. Rather than having multiple pipe networks for other subsystem, such as transfer, refuel, and jettison, a combined philosophy is pursued. The transfer system has the capability of transferring fuel between any tanks. This enables fuel use for trimming the aircraft at high speeds, rather than deploying aerodynamic controls, which have a large drag penalty. The fuel system is capable of being refuelled in 20 minutes using standard refuelling trucks. The jettison system is used in case of an emergency and the fuel is jettisoned from the aft fuselage, near the apex.

\section{F. Avionics}

The avionics team mainly develop the integrated 4D flight management system (4DFMS), hazard detection and avoidance system (HDAS), and smart cockpit display and control system (SCDCS).

Integrated 4DFMS and HDAS aim to reduce the pilot workload by avoiding low priority potential conflicts through the flight management system instead of alerting the pilots through aural and visual outputs. 4DFMS operates with Performance Based Navigation (PBN), a technique taking full advantage of available airspace and making the flight safe and efficient.

The SCDCS has been designed and Developed to provide a paper-less cockpit and interactive cockpit. The SCDCS should also act as the primary display support to the flight crew, since the visibility for the pilot is limited due to the E-19 design. The SCDCS is also designed to provide voice control assistance to the pilot. 

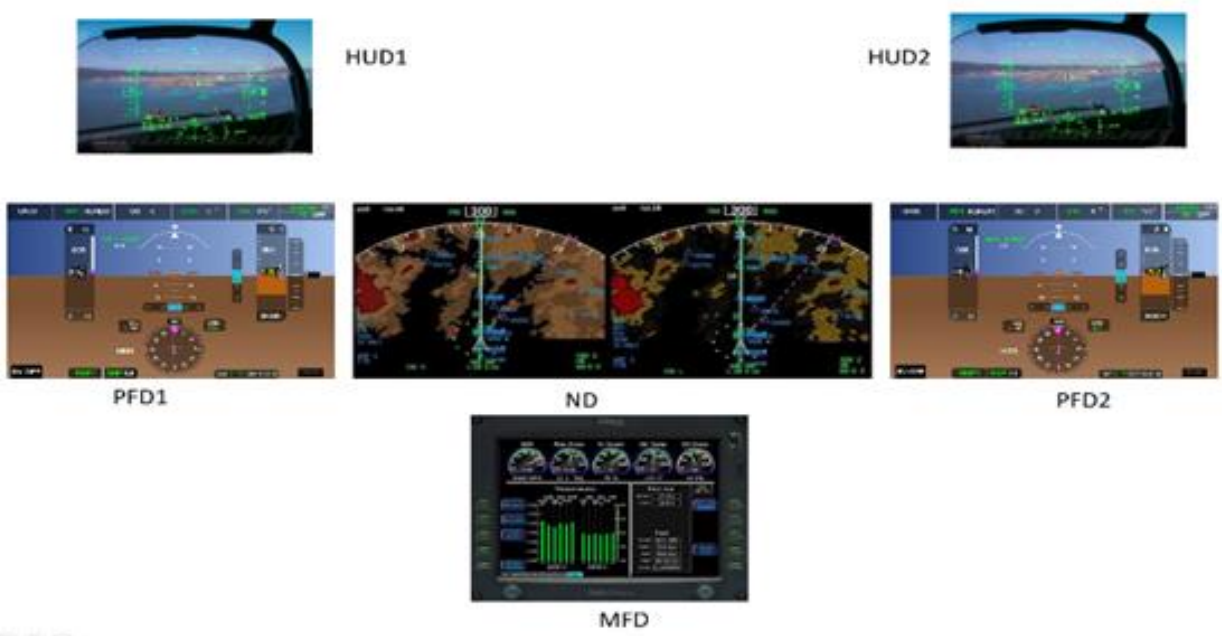

Fig. 14 Smart cockpit display and control system

\section{Key Technologies}

\section{A. Low Sonic Boom Shaping}

There is particular concern about the sonic boom intensity of the next-generation civil supersonic transport aircraft. The E-19 AEOLUS is designed to have a low sonic boom ground signature by tailoring the volume and lift distribution (Fig. 15) to separate the shocks and expansions. The resulting low sonic boom ground signature is quieter than the disruptive $\mathrm{N}$-wave boom signature. The E-19 AEOLUS has an even lower sonic boom level than its peer supersonic business jets, shown in Table 2.
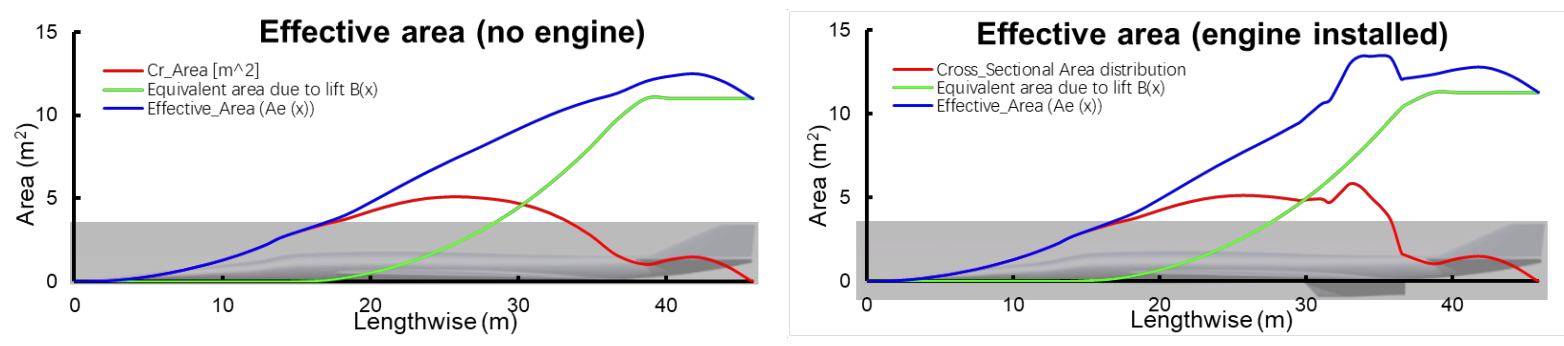

Fig. 15 Sonic boom effective areas comparison

Table 2 Sonic boom intensity of supersonic aircraft

\begin{tabular}{|l|c|c|c|}
\hline & Initial cruise (psf) & End cruise (psf) & Average (psf) $^{*}$ \\
\hline E-19 (no engine) & 1.00 & 0.82 & 0.91 \\
\hline E-19 (engine installed) & 1.19 & 0.99 & 1.09 \\
\hline Gulfstream SSBJ concept & - & - & 1.20 \\
\hline ONERA+JAXA concept & - & - & 1.20 \\
\hline E-5 Neutrino & - & - & 1.70 \\
\hline Concorde & - & - & 2.08 \\
\hline
\end{tabular}

\section{B. Hybrid Laminar Flow Control}

The hybrid laminar flow control (HLFC) system is studied in the GDP for its feasibility. The laminar flow fraction is expected to increase from 5\% to $30 \%$, leading to a reduction in friction drag of $9.2 \%$. HLFC employs suction at the leading edge and the aft region relies on aerofoil shaping to produce a favourable pressure gradient. The hybrid laminar

\footnotetext{
* estimated values
} 
flow control system power requirement has been estimated from the suction flow required and from the pressure difference over the upper and lower surfaces of the wing. The system requirements can be found in Table 3 .

Table 3 System key specifications

\begin{tabular}{|l|c|}
\hline Weight & $202 \mathrm{~kg}$ \\
\hline Total suction flow rate & $12.07 \mathrm{~m}^{3} / \mathrm{s}$ \\
\hline Suction power requirement & $91.16 \mathrm{~kW}$ \\
\hline
\end{tabular}

\section{Synthetic Vision System}

The E-19 Aelous is streamlined for low boom, low drag supersonic flight and has a long-pointed nose for improved aerodynamic efficiency. During take-off and landing, the aircraft reaches high angles of attack, due to the delta wing's lift generation at low speeds. Such high angles of attack and the streamlined nose, restrict the pilot's field of view. To enhance the vision during take-off, landing and taxing operations, the digitalized synthetic vision system is used in the E-19 AEOLUS baseline design as pictured in Fig. 16.

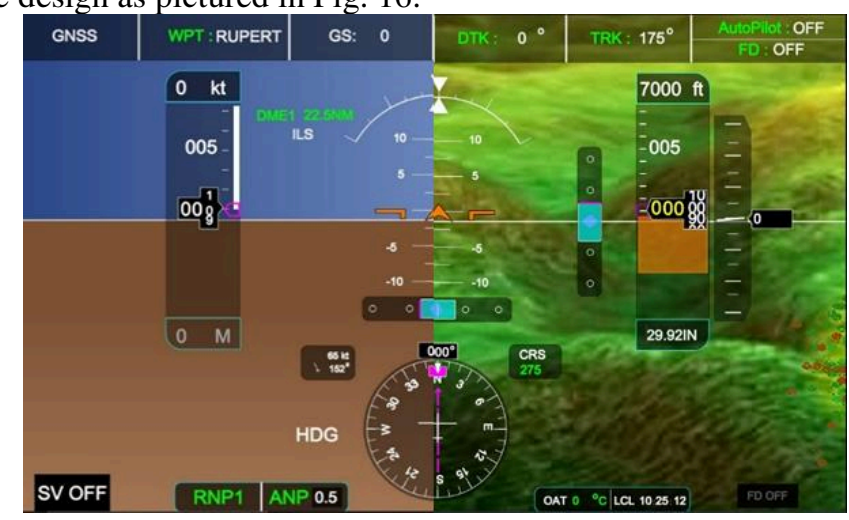

Fig. 16 Synthetic vision display

\section{Double Drooping Nose Design}

The drooping nose design is an alternative variant to the baseline design with its Synthetic Vision System. The purpose of the drooping nose is to enhance pilot's frontal natural field of view. To ensure that the drooped long pointed nose does not result in a ground strike, a double droop nose system is necessary, as pictured in Fig. 17. The nose drooped vision is illustrated in Fig. 18. The nose is hydraulically actuated with electro hydrostatic actuators (EHA) for the first droop of $8^{\circ}$ down and electromechanical actuators (EMA) for the second droop which is moved up by $6^{\circ}$. Both structures move at rate of $0.1 \mathrm{~m} / \mathrm{sec}$.

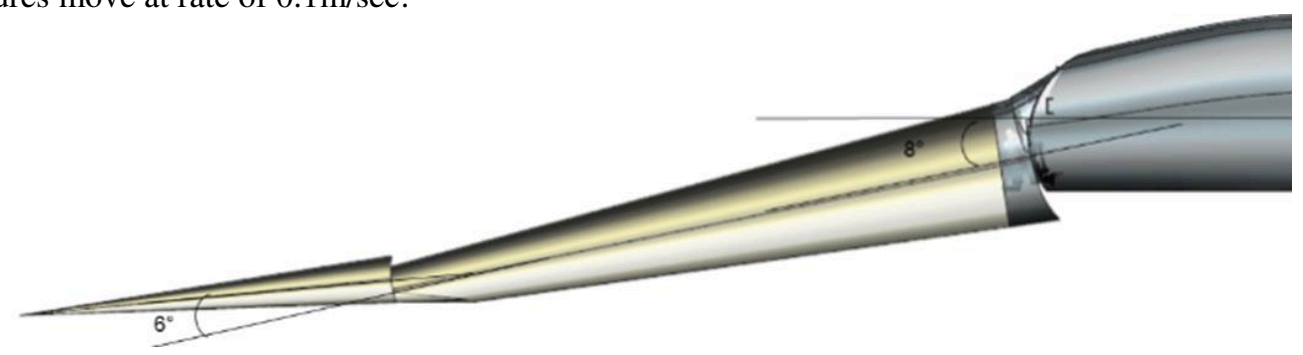

Fig. 17 Double drooping nose configuration 


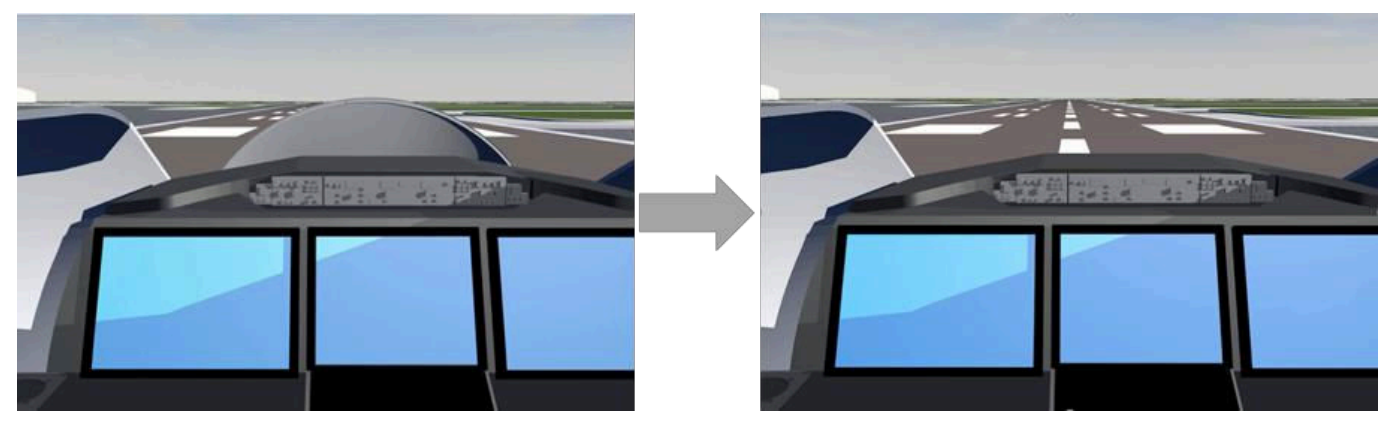

Fig. 18 Nose drooped vision

Each actuation system has a locking system with a proxy sensor to determine the locking condition and an independent locking system with a feedback sensor. Both actuation systems have a "no-back" mechanism, which prevents loads from propagating from the structure to the actuators in case of sudden impacts or high "g" loads. In the case of loss in electric power, the nose can be lowered manually using a clutch that detaches the hydraulic systems and unlocks it from the retracted condition. The nose then moves downward under the force of gravity. This redundancy is required as the complete loss of field visibility is considered a catastrophic failure. The whole system is designed and integrated in the constrained space without compromising the safety of the system. All along the system design process, system complexity, weight, manufacturing issues, costs, and reliability have been taken into consideration.

\section{Conclusion}

In this study, a supersonic business jet with low-boom and low-drag features is designed through a conceptual design phase and a preliminary design phase. The Group Design Project extends the conceptual design to detailed layout of cabin, structures, landing gears, powerplant, subsystems, and avionics.

There are many challenges associate with the civil supersonic airliners. This preliminary design of the E-19 AEOLUS case study highlights a number of specific issues and demonstrates possible solutions (e.g. the double drooping nose design). The importance of the study is to prove the low-boom low-drag design's feasibility in terms of the requirements of structures and subsystems.

\section{Acknowledgments}

The authors would like to thank Prof. Shijun Guo, Dr. Craig Lawson, Dr. Ioannis Giannopoulos, Dr. Huamin Jia, Dr. Wenli Liu, Mr. Jack Stockford, Dr. Adrian Clark, and all the 37 MSc students for their work in the group design project.

\section{References}

[1] Smith, H. "A Review of Supersonic Business Jet Design Issues," Aeronautical Journal, Vol. 111, No. 1126, 2007, pp. 761-776. doi: $10.1017 /$ S0001924000001883

[2] Sun, Y., and Smith, H. "Review and Prospect of Supersonic Business Jet Design," Progress in Aerospace Sciences, Vol. 90, 2017, pp. 12-38.

doi: 10.1016/j.paerosci.2016.12.003

[3] Smith, H., Sziroczák, D., Abbe, G. E., and Okonkwo, P. "The GENUS Aircraft Conceptual Design Environment," Proceedings of the Institution of Mechanical Engineers, Part G: Journal of Aerospace Engineering, Vol. 233, No. 8, 2018, pp. 2932-2947. doi: $10.1177 / 0954410018788922$

[4] Abbe, G. E. "Conceptual Design Methodologies for Small Solar Powered Unmanned Aerial Vehicle," Ph.D., School of Aerospace Transport and Manufacturing, Cranfield University, Bedford, UK, 2015

[5] Sziroczak, D. "Conceptual Design Methodologies Appropriate to Hypersonic Space and Global Transportation Systems," Ph.D., School of Aerospace Transport and Manufacturing, Cranfield University, Bedford, UK, 2015

[6] Okonkwo, P. P. C. "Conceptual Design Methodology for Blended Wing Body Aircraft," Ph.D., School of Aerospace Transport and Manufacturing, Cranfield University, Bedford, UK, 2016 
[7] Sun, Y., and Smith, H. "Turbofan Airliner Conceptual Design in Multidisciplinary Design Analysis Optimization Environment," 1st International Conference in Aerospace for Young Scientists, Beijing, P.R.China, 2016.

[8] Sepulveda, E., Smith, H., and Sziroczak, D. "Multidisciplinary Analysis of Subsonic Stealth Unmanned Combat Aerial Vehicles," CEAS Aeronautical Journal, Vol. 10, 2018, pp. 431-442.

doi: 10.1007/s13272-018-0325-0

[9] Sun, Y., and Smith, H. "Supersonic Business Jet Conceptual Design in a Multidisciplinary Design Analysis Optimization Environment," 2018 AIAA/ASCE/AHS/ASC Structures, Structural Dynamics, and Materials Conference, Kissimmee, Florida, 2018.

[10] Sun, Y., and Smith, H. "Sonic Boom and Drag Evaluation of Supersonic Jet Concepts," 2018 AIAA/CEAS Aeroacoustics Conference, Georgia, Atlanta, 2018.

[11] Sun, Y., and Smith, H. "Low-boom low-drag optimization in a multidisciplinary design analysis optimization environment," Aerospace Science and Technology, Vol. 94, 2019, p. 105387. doi: $10.1016 / j$.ast.2019.105387

[12] Sun, Y., and Smith, H. "Low-boom low-drag solutions through the evaluation of different supersonic business jet concepts," Aeronautical Journal, Vol. 124, No. 1271, 2019, pp. 76-95. doi: 10.1017/aer.2019.131

[13] Raymer, D. P. Aircraft Design: A Conceptual Approach, Sixth Edition, AIAA, Inc., Reston, VA, 2018.

[14] Saaris, G. R., Tinoco, E., Lee, J., and Rubbert, P., "A502I User's Manual-PAN AIR Technology Program for Solving Problems of Potential Flow about Arbitrary Configurations," Boeing Document, 1992

[15] Gur, O., Mason, W. H., and Schetz, J. A. "Full-Configuration Drag Estimation," Journal of Aircraft, Vol. 47, No. 4, 2010, pp. 1356-1367.

doi: $10.2514 / 1.47557$

[16] Harris, R. V., "An Analysis and Correlation of Aircraft Wave Drag," NASA TM X-947, 1964 


\title{
Cranfield University
}

CERES https://dspace.lib.cranfield.ac.uk

School of Aerospace, Transport and Manufacturing (SATM)

2020-06-08

Design case of the E-19 AEOLUS

supersonic business jet

\author{
Smith, Howard
}

AIAA

Smith H and Sun Y. (2020) Design case of the E-19 AEOLUS supersonic business jet. In: AIAA Aviation 2020 Forum, 15-19 June 2020, Virtual Event

https://doi.org/10.2514/6.2020-2618

Downloaded from Cranfield Library Services E-Repository 